\title{
USE OF STRONG MOTION DURATION FOR RAPID EVALUATION OF FAULT PARAMETERS
}

\author{
Yasuo IzUTANI* and Tomowo HiRasawa** \\ * Department of Civil Engineering, Faculty of Engineering, \\ Shinshu University, Nagano, Japan \\ ** Observation Center for Earthquake Prediction, \\ Faculty of Science, Tohoku University, \\ Sendai, Japan
}

(Received February 20, 1987; Revised June 19, 1987)

\begin{abstract}
A simple method is developed for rapid determination of fault parameters of a large shallow earthquake from the azimuthal dependence in duration of strong ground motion. The fault length and the direction of rupture propagation can be evaluated by this method within a short time after the earthquake origin time. As an example, the fault parameters are determined for the Tokachi-Oki earthquake of May 16, 1968. They are consistent with the main rupture process revealed by other investigators from far-field long-period seismic records, near-field strong motion records and aftershock distribution. Thus, the present method may be applicable to near-field tsunami warning, provided that a sufficient number of digital accelerographs are installed with a good azimuthal coverage.
\end{abstract}

\section{Introduction}

It is widely known that an azimuth effect due to the rupture propagation of a finite fault can be detected on the observed radiation patterns of long-period body waves and surface waves. By analyzing the azimuth effect, a number of studies have been done to reveal the source processes of moderate to large earthquakes. Recently, BOATWRIGHT and BOORE (1982) have found that an azimuth effect can be seen also on the amplitudes of near-field accelerograms. They have shown that the directivity is caused by the rupture propagation. IzUTANI and HIRASAWA (1984) have pointed out that an azimuth effect is detectable on strong motion duration, which is defined as the time interval between $5 \%$ and $85 \%$ of cumulative power curve obtained from 5 to $10 \mathrm{~Hz}$ band-pass filtered ground acceleration. The purpose of the present study is to develop a simple method for rapidly evaluating the fault length and the direction of rupture propagation by making use of the directivity on observed strong motion durations.

It is of great importance to obtain information about an earthquake source immediately after the earthquake occurrence, because the information is useful for 
near-field tsunami warning. KANAMORI and GivEN $(1981,1983)$ have presented a method for rapid evaluation of 'tsunami potential', which is a scale to express the vertical sea-bottom deformation due to an earthquake, by using near-field longperiod seismic waves. KANAMORI (1985) has carried out some numerical experiments to show the utility of the above mentioned method in the areas of Alaska and Aleutian. OKAL and TALANDIER (1986) have proposed the use of T-wave duration for rapid determination of the moment magnitude $M_{\mathrm{w}}$, and shown the applicability of their method to tsunami warning.

For reducing tsunami disasters, it is desirable to issue a precise tsunami warning which includes the arrival time and the height of an approaching tsunami at an arbitrary coast. Since the capability of a digital computer and the computational technique have been greatly improved, the numerical simulation of tsunami propagation is now possible within a few minutes (GoTO and SHUTO, 1985). Therefore, if static fault parameters needed to calculate sea-bottom deformation are obtained within several minutes after the origin time of an earthquake, it would be possible to issue a precise tsunami warning.

For the purpose of evaluating two important fault parameters, the fault length and the direction of rupture propagation, the azimuth effect on strong motion durations derived from accelerograms will be used in the present study, because seismic records by digital accelerograph at observation stations with epicentral distances less than several hundred kilometers may be the most useful data available immediately after the earthquake occurrence. In order to issue the tsunami warning before a tsunami arrives, on-line data processing may be indispensable. Hence, we give top priority to simplicity, not to completeness, in our method.

\section{Method}

\subsection{Apparent duration of fault rupture}

Figure 1 schematically illustrates a long rectangular faults, whose length is much longer than the width, and a seismic ray toward an observation station in a homogeneous infinite medium. The fault rupture is assumed to be propagated bilaterally along the fault length as indicated by broad arrows in Fig. 1. The apparent duration, $d$, of the fault rupture observed at the station, for example, is given by the time interval between the first and the last arrival of S-waves. To a farfield approximation in which the epicentral distance is large compared with the fault length, $d$ is expressed as

$$
\begin{aligned}
& d=\max \left[d^{\mathrm{L}}, d^{\mathrm{S}}\right], \\
& d^{\mathrm{L}}=(1-\varepsilon) l\{1-(v / \beta) \cos \theta\} / v, \\
& d^{\mathrm{S}}=\varepsilon l\{1+(v / \beta) \cos \theta\} / v .
\end{aligned}
$$

The top equation of Eq. (1) means that $d$ is equal to the larger value between $d^{\mathrm{L}}$ and $d^{\mathrm{S}}$. An asymmetric bilateral fault is considered here. The total fault length, $l$, is the 


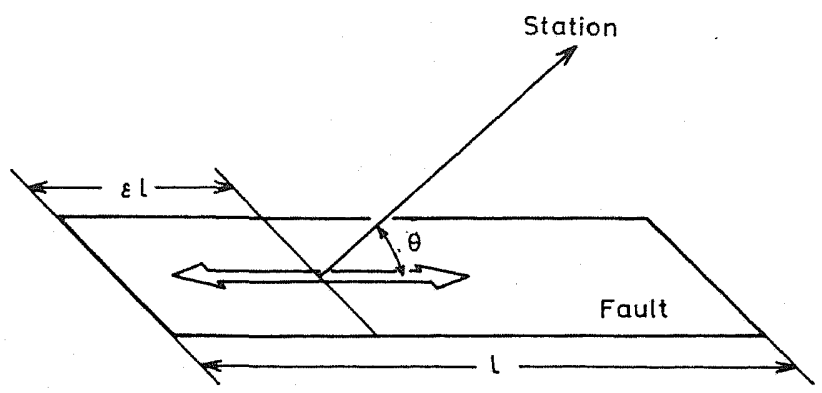

Fig. 1. Geometrical relation between a fault and an observation station in a homogeneous infinite medium. $l$ is the total length of the asymmetric bilateral fault and $\varepsilon l$ is the length of the shorter part of the fault. The fault rupture is assumed to be propagated bilaterally as indicated by the broad arrows. $\theta$ is the angle between the direction of rupture propagation on the longer part of the fault and the take-off direction of seismic waves toward the station.

sum of $\varepsilon l$ and $(1-\varepsilon) l$, where $0 \leqq \varepsilon \leqq 0.5 . v$ is the rupture velocity, $\beta$ is the S-wave velocity, and $\theta$ is the angle between the direction of rupture propagation on the longer part of the bilateral fault and the take-off direction of seismic waves toward the observation station.

\subsection{Use of strong motion duration}

We intend to estimate the apparent duration of fault rupture defined in Eq. (1) from the analysis of accelerograms recorded at observation stations with epicentral distances less than several hundred kilometers. S-waves are generally predominant on accelerograms, but we can hardly read objectively arrival times of the first and the last S-waves. It is thus necessary to introduce a new parameter for the apparent duration, $d$. We propose in this section the use of strong motion duration, $D$, as an objectively definable substitute for $d$.

TRIFUNAC and BRADY (1975) defined the strong motion duration as the time interval required for the Husid plot, which is the cumulative power curve of ground acceleration normalized by the total power, to increase from 0.05 to 0.95 . According to DOBRY et al. (1978), the Husid plots derived from accelerograms of horizontal component observed at rock sites usually showed a simple linear function of time from the onset of S-waves, because the energy of direct S-waves was predominant on the accelerograms. On the other hand, the Husid plots from accelerograms at soft sites showed a gradual increase following the linear portion, and the gradual increase was generally due to the energy of low-frequency components transmitted by surface waves. Accordingly, the strong motion duration as defined by TRIFUNAC and BRADY (1975) at soft sites for the same earthquake would increase with the distance, because the arrival time difference between surface waves and S-waves increases with the distance. 
Since we want to obtain information about earthquake source in the present study, it is undesirable for the strong motion duration to be variable with the source-to-site distance. In order to remove the effect of surface waves, we pass an acceleration data, $x(t)$, through a band-pass filter between 5 and $10 \mathrm{~Hz}, h(t)$. The Husid plot, $P(t)$, is thus defined by

$$
P(t)=\int_{0}^{t}\left\{x\left(t^{\prime}\right) * h\left(t^{\prime}\right)\right\}^{2} \mathrm{~d} t^{\prime} / \int_{0}^{T}\left\{x\left(t^{\prime}\right) * h\left(t^{\prime}\right)\right\}^{2} \mathrm{~d} t^{\prime},
$$

where the asterisk indicates the convolution, and $T$ is the total duration of $x(t)$. We define the strong motion duration, $D$, as the time interval required for the Husid plot, $P(t)$, of the filtered ground acceleration to increase from 0.05 to 0.85 . Here, these particular values of 0.05 and, in particular, 0.85 were so chosen that $D$ might
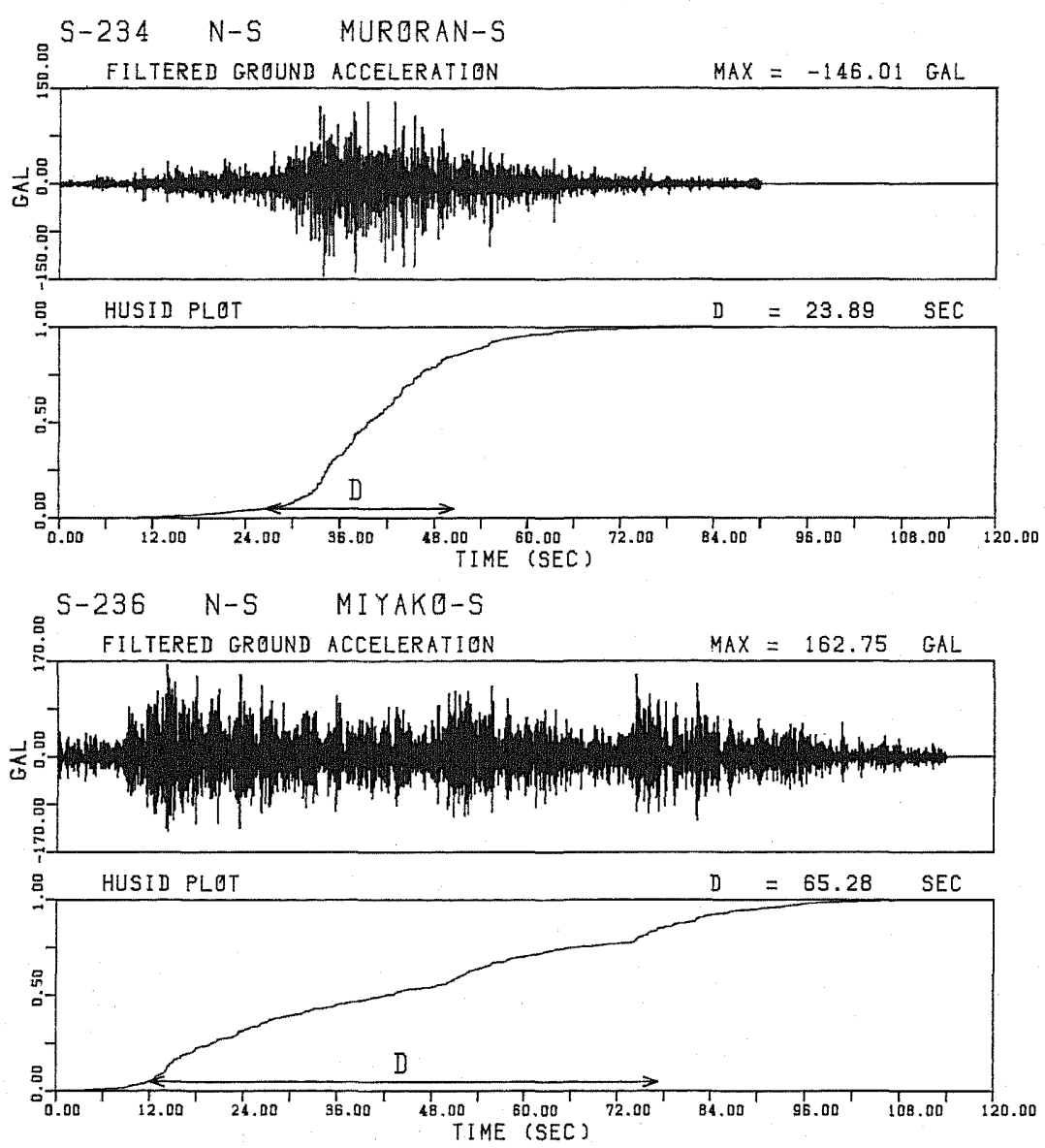

Fig. 2. Examples of 5 to $10 \mathrm{~Hz}$ band-pass filtered ground acceleration and Husid plot. $D$ denotes the strong motion duration. Both examples are derived from $\mathrm{N}-\mathrm{S}$ component accelerograms due to the 1968 Tokachi-Oki earthquake. 
not be affected significantly by an error in the estimated value of the total record length $T$. In other words, we do not have to define so rigorously either the onset time or the termination time of the seismic ground motion on a seismogram. IZUTANI (1983) pointed out that the strong motion duration thus defined is almost independent of the source-to-site distance and has positive correlation with the fault length of the earthquake.

Examples of filtered ground acceleration and Husid plot are shown in Fig. 2. The strong motion duration, $D$, is obtained objectively from the Husid plot. Both examples are derived from N-S component accelerograms due to the Tokachi-Oki earthquake of May 16, 1968. It can be seen that the strong motion durations at different observation stations, Muroran-S and Miyako-S, are very different from each other. This difference may be caused by the directivity due to the rupture propagation and also by the condition of surface layers at the stations.

Since both $D$ and $d$ have positive correlations with the fault length, we assume a simple relation between $D$ and $d$ as

$$
D=A d+B,
$$

where $A$ and $B$ are constants which may reflect characteristics of surface layers at each observation station. For simplicity, $A$ and $B$ are assumed to be site constants pertinent to each observation station and independent of the source characteristics. Although Eq. (3) may be a crude approximation for the 'real' relation between $D$ and $d$, we have no positive reason at present for assuming a more sophisticated functional form.

From Eqs. (1) and (3), expressions for $D$ are obtained as

$$
\begin{aligned}
& D=\max \left[D^{\mathrm{L}}, D^{\mathrm{S}}\right], \\
& D^{\mathrm{L}}=A(1-\varepsilon) l\{1-(v / \beta) \cos \theta\} / v+B, \\
& D^{\mathrm{S}}=A \varepsilon l\{1+(v / \beta) \cos \theta\} / v+B .
\end{aligned}
$$

These expressions suggest that an azimuth effect due to rupture propagation of a finite fault may be detected through the analysis of observed strong motion durations.

\subsection{Preparatory procedure}

If a sufficient number of data from many earthquakes are available, it is theoretically possible to determine simultaneously the site constants of $A$ and $B$, in addition to the fault parameters. Because of our intention to utilize our method for tsunami warning, however, the site constants should be known parameters in evaluating the fault parameters. Moreover, since the number of data available is limited in the present case, the simultaneous determination of all the parameters is practically impossible.

If we have data from many past earthquakes whose parameters, $\varepsilon, l, v$, and $\theta$, are known, we may be able to estimate the site constants for each observation 
station directly from Eq. (4). Unfortunately, however, we know only the earthquake magnitude in most cases of the earthquakes. A further assumption is necessary to determine $A$ and $B$.

Since the observed strong motion duration, $D$, has a positive correlation with the fault length, $l$, (IZUTANI, 1983), we assume in the present preparatory procedure a linear relation between $D$ and $l$ as

$$
D=a l+b,
$$

by neglecting the directivity effect due to rupture propagation as expressed in Eq. (4). The coefficients, $a$ and $b$, can easily be obtained through a least squares analysis of strong motion durations observed at each station. In this process, we use the values of $l$ which have been determined by previous studies through the analyses of aftershock distribution, far-field long-period seismic waves, and so on. For earthquakes whose fault length has not been presented, $l$ is estimated by the empirical formula of OTSUKA (1964);

$$
\log l=0.5 M-1.8,
$$

where $M$ is the earthquake magnitude by the Japan Meteorological Agency (JMA) and $l$ is in $\mathrm{km}$.

By comparing Eqs. (4) and (5), the following approximate relation between $a$ and $A$ should hold;

$$
a=(\overline{F / v}) A,
$$

where the bar means an average value for the earthquakes used at each station, and $F$ is

$$
\begin{aligned}
& F=\max \left[F^{\mathrm{L}}, F^{\mathrm{S}}\right], \\
& F^{\mathrm{L}}=(1-\varepsilon)\{1-(v / \beta) \cos \theta\}, \\
& F^{\mathrm{S}}=\varepsilon\{1+(v / \beta) \cos \theta\} .
\end{aligned}
$$

Since the value of $(\overline{F / v})$ cannot be determined from the observations, the theoretical expectation of $F$ with respect to $\varepsilon$ and $\theta$ is numerically calculated by using Eq. (8) and by assuming uniform distributions of $\varepsilon(0 \leqq \varepsilon \leqq 0.5)$ and $\theta$ (in all directions). The expectation of $F$ is about 0.8 when $v / \beta$ is 0.75 . Therefore, Eq. (7) can be approximated by

$$
A=a \bar{v} / 0.8,
$$

where $\bar{v}$ is an average value of $v$.

For a relation between $B$ and $b$,

$$
B=b
$$

is obtained by comparing the constant terms in Eqs. (4) and (5). 


\subsection{Main procedure}

Substituting Eqs. (9) and (10) into Eq. (4), we obtain

$$
\begin{aligned}
& D=\max \left[D^{\mathrm{L}}, D^{\mathrm{S}}\right], \\
& D^{\mathrm{L}}=(a \bar{v} / 0.8 v)(1-\varepsilon) l\{1-(v / \beta) \cos \theta\}+b, \\
& D^{\mathrm{S}}=(a \bar{v} / 0.8 v) \varepsilon l\{1+(v / \beta) \cos \theta\}+b,
\end{aligned}
$$

where $v$ is the rupture velocity of an earthquake whose fault parameters are to be evaluated, and $\bar{v}$ is the average value of rupture velocities of earthquakes whose data were used to estimate $a$ and $b$ in the preparatory procedure.

Now we assume that the fault rupture is propagated in the horizontal direction, that is, along the fault strike. The observational results by, for example, Kanamori (1970a,b, 1971), Abe (1973), and Kanamori and Cipar (1974) show that this assumption may be reasonable for large shallow earthquakes. Then, considering the S-wave propagation in the actual earth's materials, we replace $\cos \theta$ in Eq. (11) by

$$
\cos \theta=\cos (\phi-\alpha) \sin \gamma,
$$

where $\phi$ is the direction of rupture propagation on the longer part of the fault, and $\alpha$ is the azimuth of the observation station. Both $\phi$ and $\alpha$ are measured clockwise from the north at the epicenter. $\gamma$ is the take-off angle of S-waves, and

$$
\sin \gamma=\beta / c,
$$

where $\beta$ is the $\mathrm{S}$-wave velocity at the source region and $c$ is the apparent velocity of S-wave.

Considering a small quantity of data in the present case, we introduce the following two assumptions to decrease the number of unknown parameters;

$$
v=\bar{v}
$$

and

$$
\bar{v} / c=0.6
$$

The assumption of Eq. (14) means that the rupture velocity of the earthquake, whose fault parameters are to be evaluated, is assumed to be equal to $\bar{v}$. This assumption may be acceptable, because rupture velocities of earthquakes in the same region may reflect a local tectonic condition and may not be very different from one another.

According to GELLER (1976) who compiled the source parameters of many large earthquakes, rupture velocity ranges from 1.4 to $4.0 \mathrm{~km} / \mathrm{s}$. The apparent velocity of S-wave propagated from a shallow focus to an observation station with an epicentral distance of a few hundred kilometers may be about 4 or $5 \mathrm{~km} / \mathrm{s}$, which is nearly equal to the S-wave velocity just below the Moho. Hence, as in Eq. (15), 0.6 seems to be a good approximation to $\bar{v} / c$. 
From Eqs. (11), (12), (13), (14), and (15), we obtain

$$
\begin{aligned}
& D=\max \left[D^{\mathrm{L}}, D^{\mathrm{S}}\right], \\
& D^{\mathrm{L}}=(a / 0.8)(1-\varepsilon) l\{1-0.6 \cos (\phi-\alpha)\}+b, \\
& D^{\mathrm{S}}=(a / 0.8) \varepsilon l\{1+0.6 \cos (\phi-\alpha)\}+b .
\end{aligned}
$$

Owing to the assumptions of Eqs. (14) and (15), the remaining unknown parameters are $\varepsilon, l$, and $\phi$ for an earthquake. They are estimated through the main procedure by minimizing the sum of squares of residuals between observed strong motion durations and those calculated by Eq. (16). It may be understood from Eq. (16) that the estimation of these parameters is rather insensitive to the assumed value of $\bar{v} / c$, because $\bar{v} / c$ is a coefficient for the term expressing the azimuthal variation of strong motion duration.

\section{Example}

\subsection{Data}

We analyze 104 horizontal component accelerograms from 32 earthquakes listed in Table 1. These accelerograms were recorded with SMAC-B2-type accelerographs operated by the Port and Harbour Research Institute at five observation stations, Kushiro-S, Muroran-S, Aomori-S, Hachinohe-S, and Miyako-S, in

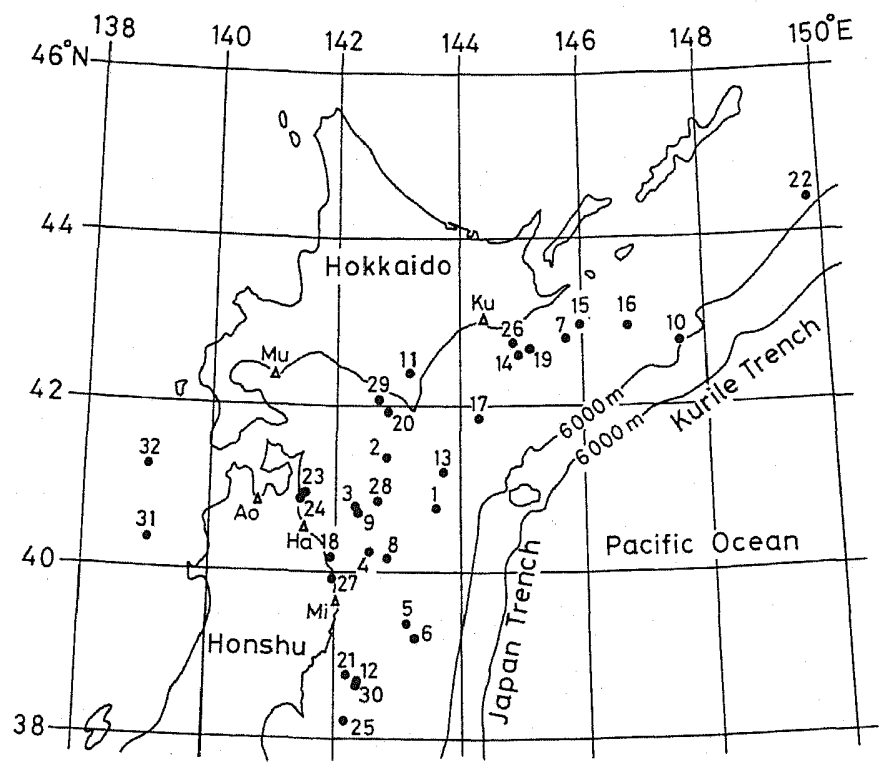

Fig. 3. Earthquake epicenters and locations of observation stations. The solid circles indicate epicenters and the attached numbers correspond to those in Table 1. The triangles indicate observation stations; Kushiro-S $(\mathrm{Ku})$, Muroran-S (Mu), Aomori-S (Ao), Hachinohe-S (Ha), and Miyako-S (Mi). 
Table 1. List of earthquakes.*

\begin{tabular}{|c|c|c|c|c|c|c|}
\hline No. & $\begin{array}{c}\text { Date** } \\
\text { (Year.Month.Day) }\end{array}$ & $\begin{array}{l}\text { Latitude } \\
\text { (N) }\end{array}$ & $\begin{array}{l}\text { Longitude } \\
\text { (E) }\end{array}$ & $\begin{array}{l}\text { Depth } \\
(\mathrm{km})\end{array}$ & $M$ & $\begin{array}{l}\text { Fault length } \\
\qquad(\mathrm{km})\end{array}$ \\
\hline 1 & 1968. 5.16 & 40.733 & 143.583 & 0.0 & 7.9 & $150^{11}$ \\
\hline 2 & 1968. 5.16 & 41.417 & 142.850 & 40.0 & 7.5 & \\
\hline 3 & 1968. 5.17 & 40.750 & 142.333 & 40.0 & 5.9 & \\
\hline 4 & 1968. 5.23 & 40.250 & 142.567 & 30.0 & 6.3 & $12^{21}$ \\
\hline 5 & 1968. 6.12 & 39.417 & 143.133 & 0.0 & 7.2 & $80^{31}$ \\
\hline 6 & 1968.6 .13 & 39.233 & 143.283 & 40.0 & 5.7 & \\
\hline 7 & 1968.9 .3 & 42.783 & 145.717 & 60.0 & 5.2 & \\
\hline 8 & 1968.11 .14 & 40.150 & 142.783 & 30.0 & 6.0 & \\
\hline 9 & $1969,6.21$ & 40.700 & 142.367 & 40.0 & 5.6 & \\
\hline 10 & 1969. 8.12 & 42.700 & 147.617 & 30.0 & 7.8 & $180^{4 !}$ \\
\hline 11 & 1970. 1.21 & 42.383 & 143.133 & 50.0 & 6.7 & \\
\hline 12 & 1970. 9.14 & 38.683 & 142.333 & 40.0 & 6.2 & \\
\hline 13 & 1971. 8.2 & 41.233 & 143.700 & 60.0 & 7.0 & \\
\hline 14 & 1972. 5.11 & 42.600 & 144.933 & 60.0 & 5.8 & \\
\hline 15 & 1973. 6.17 & 42.967 & 145.950 & 40.0 & 7.4 & $100^{5 /}$ \\
\hline 16 & 1973. 6.24 & 42.950 & 146.750 & 30.0 & 7.1 & \\
\hline 17 & 1974. 1.25 & 41.833 & 144.267 & 40.0 & 6.0 & \\
\hline 18 & 1974. 9.4 & 40.183 & 141.933 & 40.0 & 5.6 & \\
\hline 19 & 1974. 9.20 & 42.683 & 145.100 & 50.0 & 5.5 & \\
\hline 20 & 1975.10 .30 & 41.950 & 142.783 & 60.0 & 6.0 & \\
\hline 21 & 1978. 2.20 & 38.750 & 142.200 & 50.0 & 6.7 & $20^{61}$ \\
\hline 22 & 1978. 3.25 & 44.333 & 149.817 & 40.0 & 7.3 & $100^{7 /}$ \\
\hline 23 & 1978. 5.16 & 40.950 & 141.467 & 10.0 & 5.8 & \\
\hline 24 & 1978. 5.16 & 40.933 & 141.450 & 10.0 & 5.8 & \\
\hline 25 & 1978. 6.12 & 38.150 & 142.167 & 40.0 & 7.4 & $80^{81}$ \\
\hline 26 & 1979. 5.17 & 42.767 & 144.817 & 60.0 & 5.0 & \\
\hline 27 & 1979.10 .2 & 39.933 & 141.883 & 60.0 & 5.0 & \\
\hline 28 & 1981.12. 2 & 40.883 & 142.600 & 60.0 & 6.2 & \\
\hline 29 & 1982. 3.21 & 42.067 & 142.600 & 40.0 & 7.1 & $30^{91}$ \\
\hline 30 & 1982. 6. 1 & 38.683 & 142.333 & 40.0 & 6.2 & \\
\hline 31 & 1983. 5.26 & 40.357 & 139.073 & 14.0 & 7.7 & $100^{101}$ \\
\hline 32 & $1983,6.21$ & 41.267 & 139.000 & 6.0 & 7.1 & \\
\hline
\end{tabular}

*JMA. ** JST. $M$, Earthquake magnitude.

References: ${ }^{1)}$ KANAMORI (1971), ${ }^{21}$ IZUTANI and HiRASAWA (1978), ${ }^{3)}$ YoshioKA and Abe (1976), ${ }^{4)}$ Abe (1973), ${ }^{5}$ Shimazaki (1974), ${ }^{6)}$ Seno et al. (1978), ${ }^{7)}$ Sudo et al. (1978), ${ }^{81}$ Seno et al. (1980), ${ }^{97}$ TAKeO et al. (1982), ${ }^{10)}$ SHIMAZAKI and MORI (1983).

Hokkaido and northern Honshu, Japan (Kurata et al., 1972, 1973, 1974, 1975, 1976, 1979, 1980, 1982, $1983 \mathrm{a}, \mathrm{b}$; Tsuchida et al., 1969, $1970 \mathrm{a}, \mathrm{b}, 1971)$. The earthquake epicenters and the locations of the observation stations are shown in Fig. 3, where the earthquake numbers correspond to those in Table 1. According to JMA, the magnitudes of these earthquakes range from 5.0 to 7.9, the focal depths from 0 to $60 \mathrm{~km}$, and the epicentral distances from 30 to $460 \mathrm{~km}$. We use this data set to evaluate the site constants of $a$ and $b$ for each station and the fault parameters for the Tokachi-Oki earthquake of May 16, 1968 (No. 1 in Table 1). 

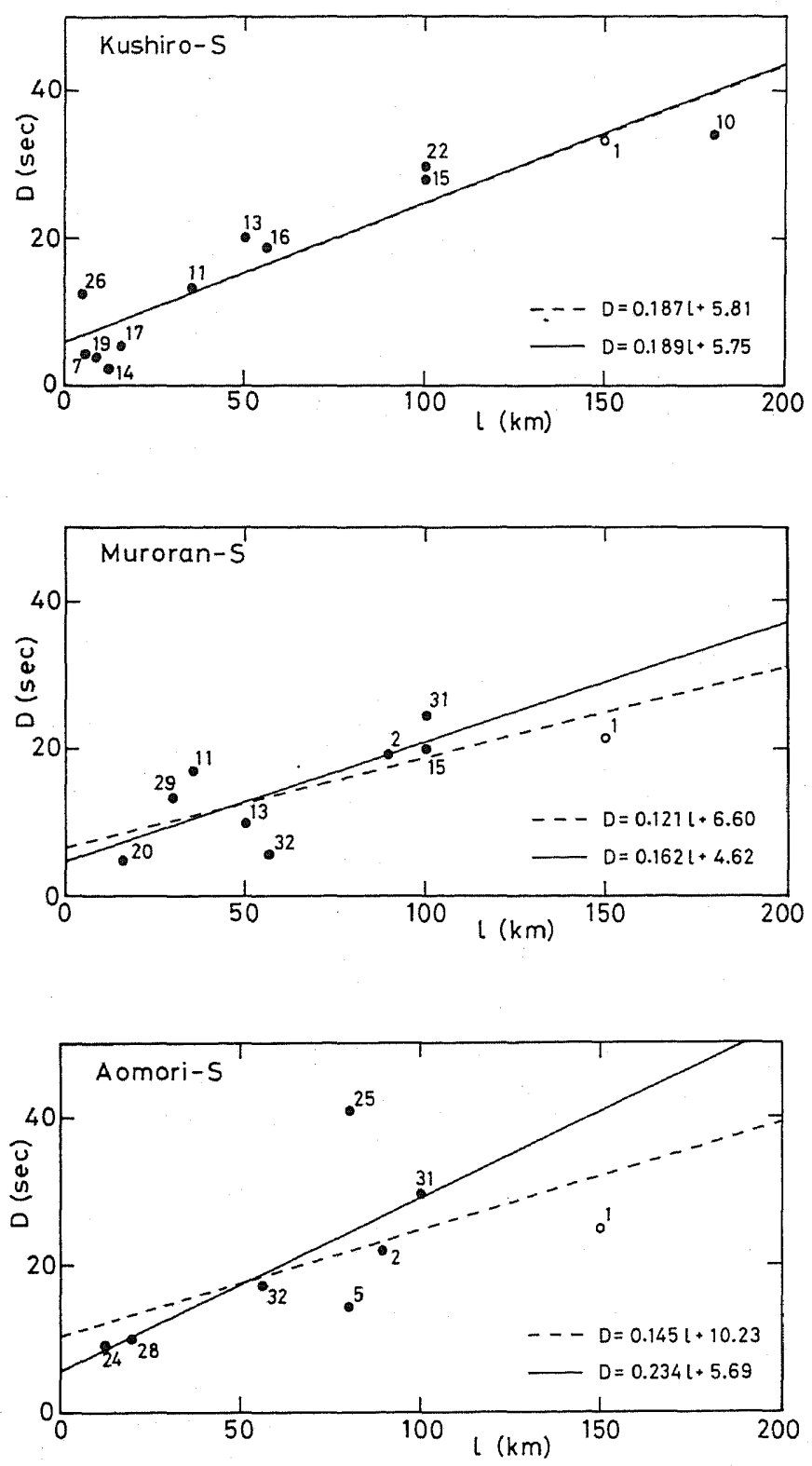

Fig. 4

\subsection{Site constants of $a$ and $b$}

Digital accelerograms are corrected by the theoretical response curve for the SMAC-B2 accelerograph (IAI et al., 1978). The corrected accelerograms are filtered by a band-pass filter between 5 and $10 \mathrm{~Hz}$ to remove the contribution from surface 

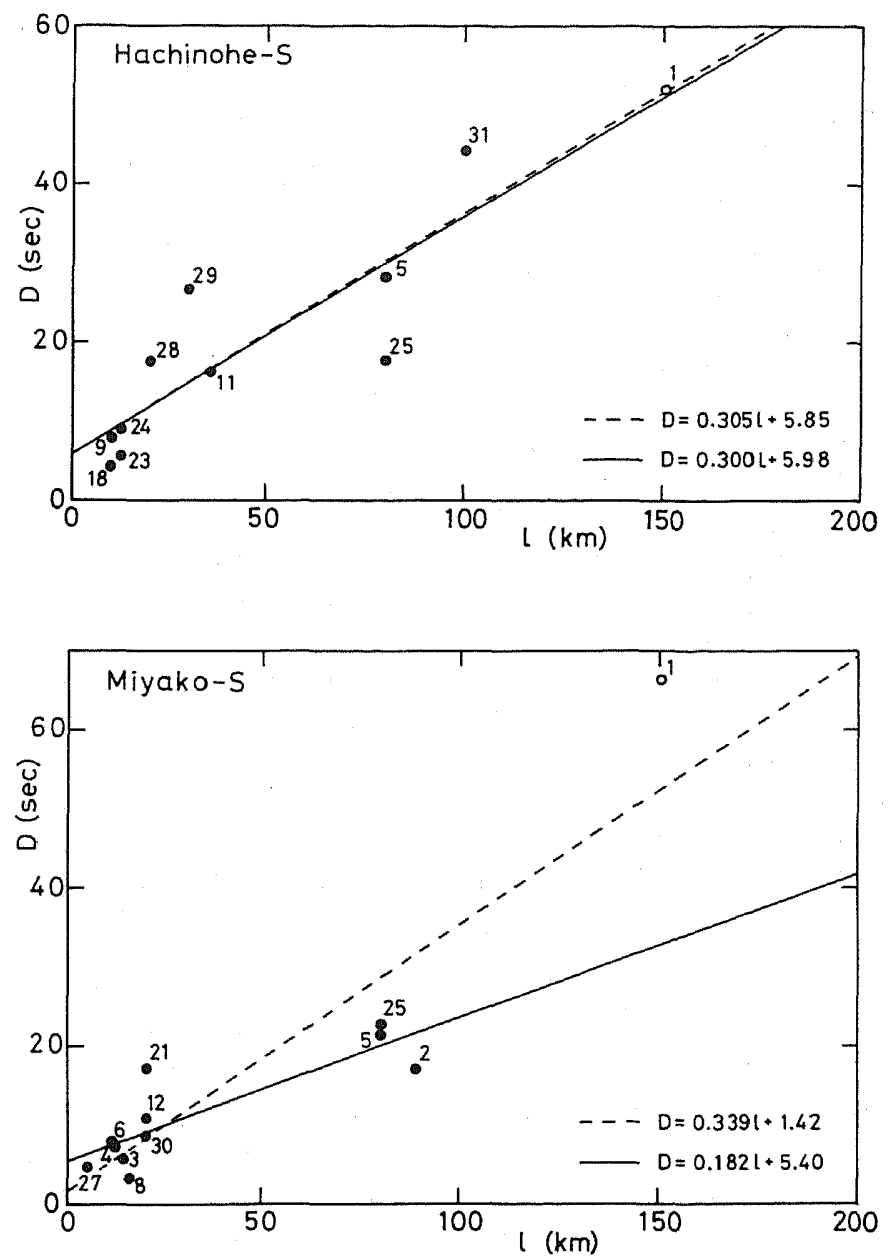

Fig. 4. Relations between the strong motion duration, $D$, and the fault length, $l$, at five observation stations. The solid and the open circles are observations, and the attached numbers correspond to those in Table 1. The dashed line denotes the least squares fit for the data including the 1968 Tokachi-Oki earthquake (Earthquake No. 1). The solid line denotes the least squares fit for the data excluding the earthquake.

waves. Then, strong motion durations are obtained as the time intervals between $5 \%$ and $85 \%$ of Husid plots as shown in Fig. 2. Strong motion durations derived from two horizontal component accelerograms at the same station from the same earthquake are generally not very different from each other, and are averaged to obtain the strong motion duration, $D$, used in the following analysis. 
A least squares analysis is carried out by means of Eq. (5) to obtain the site constants of $a$ and $b$. The results for the five observation stations are shown in Fig. 4. Two different results are shown for each station. Result-1 (dashed line in Fig. 4) is obtained from data including the 1968 Tokachi-Oki earthquake, and Result-2 (solid line) is obtained from data excluding the earthquake. Result-1 may be more reliable than Result-2, because the data set for Result- 1 is larger than that for Result- 2 . Considering the purpose of the present study, however, we will use the site constants of Result-2 in determining the fault parameters of the 1968 Tokachi-Oki earthquake.

\subsection{Fault parameters of the 1968 Tokachi-Oki earthquake}

The data set for the main procedure of the present method is listed in Table 2. The values of $a$ and $b$ are those of Result-2 obtained through the preparatory procedure. Since the reliability of $a$ and $b$ for Aomori-S and Miyako-S seems to be poor as mentioned in the previous section, we arbitrarily give smaller values to the weights of these data relative to those for the other observation stations. The five observation stations cover about 150 degrees in azimuth around the epicenter of the Tokachi-Oki earthquake.

We have only five data while there are three unknown parameters, $\varepsilon, l$, and $\phi$, in Eq. (16). We fix the value of $\varepsilon$ at $0,0.1,0.2,0.3,0.4$, or 0.5 to have a better convergence in the least squares procedure. The results of least squares analysis are listed in Table 3 (Solutions 1 to 6). The standard deviations for Solutions 1, 2, and 3 are smaller than those for the other solutions. The fault length of the longer part, $(1-\varepsilon) l$, is the same for Solutions 1,2 , and 3. It is easily understood from Eq. (16) that $D^{\mathrm{L}}$ is always larger than $D^{\mathrm{S}}$ irrespectively of azimuth when $\varepsilon$ is smaller than 0.2 . In such a case, a definite value cannot be obtained for the length of the shorter part, $\varepsilon l$. This is an inevitable limitation of the present method. In order to overcome this limitation, it is necessary, for example, to use information about the amplitude of ground acceleration together with the strong motion duration. Although we will adopt Solution 1 for $\varepsilon=0$ in the following discussion, this uncertainty of the fault length of the shorter part should be kept in mind.

Apparent fault length, $L$, defined by

Table 2. Data for the 1968 Tokachi-Oki earthquake.

\begin{tabular}{lccccc}
\hline \multicolumn{1}{c}{ Station } & $\begin{array}{c}\alpha \\
(\mathrm{deg})\end{array}$ & $\begin{array}{c}D \\
(\mathrm{~s})\end{array}$ & $\begin{array}{c}a \\
(\mathrm{~s} / \mathrm{km})\end{array}$ & $\begin{array}{c}b \\
(\mathrm{~s})\end{array}$ & $W$ \\
\hline Kushiro-S & 14.50 & 33.14 & 0.189 & 5.75 & 1.0 \\
Muroran-S & 309.72 & 21.41 & 0.162 & 4.62 & 1.0 \\
Aomori-S & 273.24 & 24.79 & 0.234 & 5.69 & 0.5 \\
Hachinohe-S & 264.16 & 52.00 & 0.300 & 5.98 & 1.0 \\
Miyako-S & 228.94 & 66.34 & 0.182 & 5.40 & 0.25 \\
\hline
\end{tabular}

$\alpha$, Azimuth; $D$, observed strong motion duration; $a$ and $b$, site constants; $W$, weight. 
Table 3. Fault parameters of the 1968 Tokachi-Oki earthquake.

\begin{tabular}{ccccc}
\hline $\begin{array}{c}\text { Solution } \\
\text { No. }\end{array}$ & $\varepsilon$ & $\begin{array}{c}l \\
(\mathrm{~km})\end{array}$ & $\begin{array}{c}\phi \\
(\mathrm{deg})\end{array}$ & $\begin{array}{c}\sigma \\
(\mathrm{s})\end{array}$ \\
\hline 1 & $0.0^{*}$ & $184.0 \pm 26.8$ & $319.9 \pm 11.5$ & 7.51 \\
2 & $0.1^{*}$ & $204.4 \pm 29.8$ & $319.9 \pm 11.5$ & 7.51 \\
3 & $0.2^{*}$ & $230.0 \pm 33.5$ & $319.9 \pm 11.5$ & 7.51 \\
4 & $0.3^{*}$ & $228.4 \pm 64.2$ & $330.9 \pm 25.5$ & 8.58 \\
5 & $0.4^{*}$ & $183.5 \pm 40.7$ & $2.0 \pm 27.3$ & 9.29 \\
6 & $0.5^{*}$ & $167.0 \pm 31.1$ & $34.5 \pm 33.7$ & 10.67 \\
\hline
\end{tabular}

* Assumed value. $\varepsilon$, Ratio of the fault length of the shorter part to the total length; $l$, total length of the fault; $\phi$, direction of the rupture propagation; $\sigma$, standard deviation.

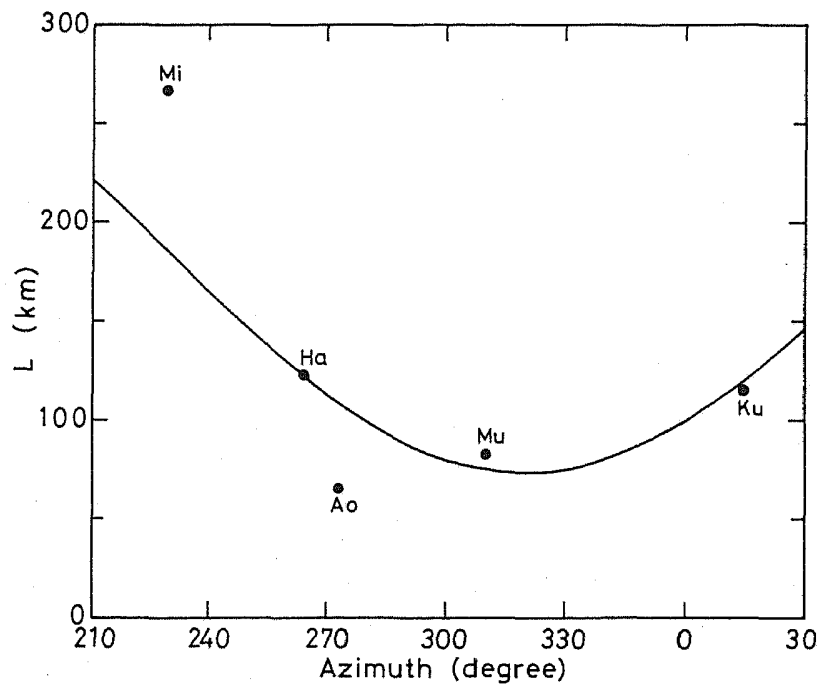

Fig. 5. Apparent fault length, $L$, plotted against station azimuth. The solid circles indicate observations for Kushiro-S (Ku), Muroran-S (Mu), Aomori-S (Ao), Hachinohe-S (Ha), and Miyako-S (Mi). The curve indicates theoretical function $L$ for Solution 1 in Table 3.

$$
L=0.8(D-b) / a
$$

is calculated from the data in Table 2 for each station and plotted against the azimuth in Fig. 5. The theoretical function $L$ of azimuth is obtained from Eqs. (16), (17), and Solution 1, and shown by the curve in Fig. 5. The theoretical curve well accounts for the data for Kushiro-S, Muroran-S, and Hachinohe-S, which seem to be more reliable than those for Aomori-S and Miyako-S as mentioned previously.

Table 4 shows the fault length and the direction of rupture propagation for the 1968 Tokachi-Oki earthquake, which have been obtained by various investigators. All the results, including the present one, are consistent with one another. The fault length is 150 to $200 \mathrm{~km}$, and the direction of rupture propagation is north to 
Table 4. The main rupture process of the 1968 Tokachi-Oki earthquake.

\begin{tabular}{lcc}
\hline & $\begin{array}{c}\text { Length } \\
(\mathrm{km})\end{array}$ & Direction \\
\hline KANAMORI $(1971)^{*}$ & 150 & - \\
KANAMORI $(1971)^{* *}$ & $150 \sim 200$ & $\mathrm{~N} \sim \mathrm{NW}$ \\
FUKAO and FURUMOTO (1975) & 150 & $\mathrm{~N} 24^{\circ} \mathrm{W}$ \\
IIDA and HAKUNO (1984) & 200 & - \\
MORI and SHIMAZAKI $(1984,1985)$ & 160 & $\mathrm{~N} \sim \mathrm{NW}$ \\
KIKUCHI and FUKAO (1985) & 160 & $\mathrm{~N} \sim \mathrm{NW}$ \\
SCHWARTZ and RUFF (1985) & 170 & $\mathrm{~N} 30^{\circ} \mathrm{W}$ \\
Present study & 184 & $\mathrm{~N} 40^{\circ} \mathrm{W}$ \\
\hline
\end{tabular}

* Based on aftershock area. ** Based on surface-wave analysis.

northwest. Further discussion about the faulting mechanism of this earthquake appears in the next section.

\section{Discussion}

We have evaluated the fault length and the direction of rupture propagation for the 1968 Tokachi-Oki earthquake in order to test the applicability of the present method to tsunami warning. Many studies have been done to reveal the faulting process of this earthquake, analyzing far-field long-period body waves, surface waves, aftershock distribution, and so on. Let us examine the present result in comparison with the results of the previous studies.

KANAMORI (1971) obtained a focal mechanism solution from P-wave first motions and long-period surface wave data; dip direction $=\mathrm{S} 66^{\circ} \mathrm{W}$, dip angle $=20^{\circ}$ for one of two P-wave nodal planes, and dip direction $=\mathrm{N} 60^{\circ} \mathrm{E}$, dip angle $=78^{\circ}$ for the other plane. The former plane was regarded as the fault plane. He observed a slight asymmetry in the radiation pattern of surface waves. Noting that his data could not resolve the details of the rupture geometry, he found that unilateral rupture propagation over a distance of 150 to $200 \mathrm{~km}$ toward north to northwest can explain the observed asymmetry. Taking the aftershock area into consideration, however, he concluded that the dimension of the fault was estimated to be $150 \times 100 \mathrm{~km}^{2}$. Figure 6 shows the epicenter location by JMA with a cross. The fault plane by KANAMORI (1971) is projected onto a horizontal plane and expressed by a solid-line rectangle.

NAGAMUNE (1971) pointed out that a remarkable phase with a large amplitude was observed at JMA stations in Hokkaido and northern Honshu. He explained this phase as the S-waves radiated from a place which is not the hypocenter of the main shock. Figure 6 shows the relative location of this $\mathrm{S}$-wave origin by a solid circle with ' $N$ '.

FUKAO and FURUMOTO (1975) carried out a detailed analysis of the long-period 


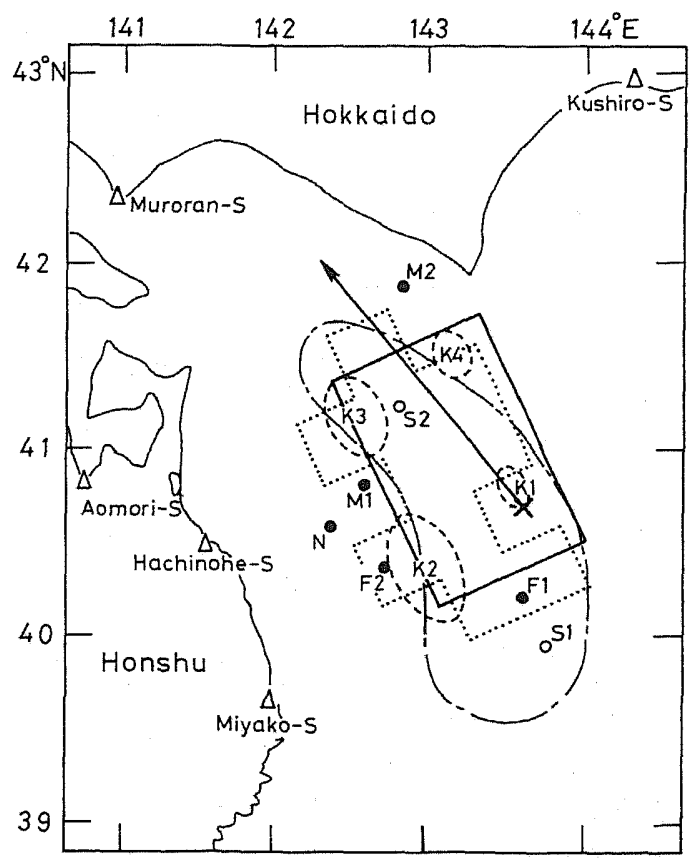

Fig. 6. Source process of the 1968 Tokachi-Oki earthquake. The cross indicates the epicenter of the earthquake by JMA. The chained curve denotes the aftershock area within $24 \mathrm{~h}$ after the main shock, and the rectangle of the solid line indicates the horizontal projection of the fault plane by KANAMORI (1971, 1974). The solid circles indicate large subevents; N by NAGAMUNe (1971), F1 and $\mathrm{F} 2$ by FUKAo and FURUMOTO (1975), M1 and M2 by MORI and SHIMAZAKI $(1984,1985)$. The area enclosed by the dotted line indicates that of strong energy release by IIDA and HAKUNO (1984). The four areas (K1, K2, K3, and K4) enclosed by the dashed curves denote those ruptured with large moment release by KIKUCHI and FUKAO (1985). Open circles indicate the starting point (S1) and the terminal point (S2) of the main rupture by SCHWARTZ and RUFF (1985). The present result (Solution 1 in Table 3) is shown by an arrow whose length and direction denote the fault length and the direction of rupture propagation.

P-waves, and found two large subevents at $57 \mathrm{~km} \mathrm{~S}$ and at $93 \mathrm{~km}$ WSW of the initial hypocenter. The locations of the subevents are indicated in Fig. 6 by solid circles with ' $\mathrm{F} 1$ ' and 'F2', respectively. They further concluded from their surfacewave analysis that the main faulting commenced about $80 \mathrm{~km}$ south of the initial epicenter with a rupture velocity of about $4 \mathrm{~km} / \mathrm{s}$, based on the assumptions of the fault length of $150 \mathrm{~km}$ and the direction of rupture propagation of $\mathrm{N} 24^{\circ} \mathrm{W}$.

IIDA and HAKUNO (1984) used an inversion method of accelerograms in order to reveal the source-rupture process corresponding to the short-period wave 
radiation. They found that strong energy was radiated from the area enclosed by the dotted line in Fig. 6.

MORI and SHIMAZAKI (1984) determined the locations of two large subevents at $97 \mathrm{~km} \mathrm{~W}$ and at $148 \mathrm{~km} \mathrm{NW}$ of the initial epicenter, analyzing short-period WWSSN records. The locations are shown in Fig. 6 by solid circles with 'M1' and 'M2', respectively. By the least squares inversion of the intermediate-period Rayleigh waves recorded at JMA stations, MORI and SHIMAZAKI (1985) found two areas with large moment release at almost the same places of the two subevents obtained previously by MoRI and SHIMAZAKI (1984). They interpreted their result as that the main rupture direction was north to northwest and the rupture length was about $160 \mathrm{~km}$.

KIKUCHI and FUKAO (1985) obtained the space-time distribution of point sources with large moment release by means of the inversion of far-field $\mathrm{P}$-waves. Four areas enclosed by broken curves, which are marked by 'K1', 'K2', 'K3', and ' $\mathrm{K} 4$ ', respectively, in Fig. 6, indicate those ruptured with large moment release in this time sequence. They concluded that the overall feature of the source process was characterized roughly by unilateral rupture propagation over a length of about $160 \mathrm{~km}$.

SCHWARTZ and RUFF (1985) carried out an analysis of the source time functions deconvolved from the observed long-period P-waves. They found that the starting point of the main rupture was at $87 \mathrm{~km} \mathrm{S10} 0^{\circ} \mathrm{E}$ of the initial hypocenter and the terminal point was at $168 \mathrm{~km} \mathrm{~N} 30^{\circ} \mathrm{W}$ of the starting point. The two points are shown by open circles with 'S1' and 'S2', respectively, in Fig. 6.

The results of these studies indicate that the 1968 Tokachi-Oki earthquake is a typical multiple shock. However, the locations of large subevents or areas with large moment release are slightly different from study to study. Although it is difficult to derive a unique conclusion for the detailed process of faulting, the overall feature of the rupture process is almost the same among these studies as seen in Table 4.

In Fig. 6, the present result is shown by an arrow, whose length and direction denote the fault length and the direction of rupture propagation. Our result is considered to be consistent with the overall feature of the rupture process derived by previous studies. The starting point of the rupture is placed at the hypocenter in our study. It is not possible for us to place the starting point at a different point, because our information is limited to those available immediately after the earthquake occurrence. If we tentatively place the starting point at ' $\mathrm{S} 1$ ', however, the present result almost coincides with that by SCHWARTZ and RUFF (1985).

It is confirmed through the above discussion that the strong motion duration is a useful tool to rapidly reveal the overall feature of rupture process for large shallow earthquakes. However, when the fault is exceptionally long, as in the case of the 1960 Chilean earthquake, the strong motion duration may not always reflect the total length of the fault, because the contribution of the wave energy from a distant part of the fault may be negligible and the Husid plot may reach 0.85 before S-wave 
arrivals from distant points. In order to cope with such a special case, an approach different from the present one will be needed.

\section{Conclusion}

For rapid evaluation of fault parameters of a large shallow earthquake, we proposed the use of strong motion accelerograms observed at stations with epicentral distances less than several hundred kilometers. The strong motion duration was defined as the time interval between $5 \%$ and $85 \%$ of the cumulative power curve that is derived from ground acceleration filtered by a band-pass filter between 5 and $10 \mathrm{~Hz}$. Thus defined strong motion duration is affected not by the source-to-station distance but by the directivity due to the rupture propagation of the fault and also by the local site conditions at observation stations.

A simple method was developed for fault parameter determination from the directivity on observed strong motion durations. With this method, the fault length and the direction of rupture propagation can be evaluated for a large shallow earthquake within several minutes after the earthquake origin time. In advance of the practical application of this method, we should determine the site constants of $a$ and $b$ which represent the site effect on the observed strong motion duration. It is important to analyze strong motion data from as many past earthquakes as possible in order to obtain reliable estimates for the site constants, because accuracy of the fault parameters estimated by the present method depends significantly on the values of $a$ and $b$.

As an example, the fault length and the direction of rupture propagation were determined for the 1968 Tokachi-Oki earthquake. They are consistent with the main rupture process that has been revealed by other investigators from far-field longperiod seismic records, near-field strong motion records, aftershock distribution, and so on.

The present method is very simple and efficient in rapidly evaluating the fault parameters. It is concluded, therefore, that the present method can be utilized for the near-field tsunami warning. From the viewpoint of its practical application, there still remain some problems to be resolved. Some of them will be discussed in more detail in a separate paper by IZUTANI and HIRASAWA (1987).

We thank Drs. H. Tsuchida, S. Noda, E. Kurata, S. Iai, and T. Fukuhara of the Port and Harbour Research Institute, Ministry of Transport, Japan, for allowing us to use the magnetic tapes of digital accelerograms. We also thank Prof. N. Shuto of the Faculty of Engineering, Tohoku University, for his invaluable suggestions. This study was supported partly by a Grant-in-Aid for Research on Natural Disasters from the Ministry of Education, Science and Culture of Japan. Calculations were made on the computers at the Computer Centers of Shinshu University and the University of Tokyo. Least squares solutions were obtained using the "Program System SALS" (NAKAGAWA and OYANAGI, 1980). 


\section{REFERENCES}

ABE, K., Tsunami and mechanism of great earthquakes, Phys. Earth Planet. Inter., 7, 143-153, 1973.

BoAtwright, J. and D. Boore, Analysis of the ground accelerations radiated by the 1980 Livermore Valley earthquakes for directivity and dynamic source characteristics, Bull. Seismol. Soc. Am., 72, 1843-1865, 1982.

DOBRY, R., I. M. IDRISS, and E. NG, Duration characteristics of horizontal components of strong-motion earthquake records, Bull. Seismol. Soc. Am., 68, 1487-1520, 1978.

FuKao, Y. and M. Furumoto, Foreshocks and multiple shocks of large earthquakes, Phys. Earth Planet. Inter., 10, 355-368, 1975.

GelleR, R. J., Scaling relations for earthquake source parameters and magnitudes, Bull. Seismol. Soc. Am., 66, 1501-1523, 1976.

Goto, C. and N. SHuTo, Accuracy and speed of numerical simulation as a means of tsunami forecasting, Proc. Inter. Tsunami Symp., 82-87, 1985.

IAI, S., E. Kurata, and H. TsuchidA, Digitization and correction of strong-motion accelerograms, Tech. Note Port Harbour Res. Inst., No. 286, 1-56, 1978 (in Japanese).

IIDA, M. and M. HAKUNO, The difference in the complexities between the 1978 Miyagi-Oki earthquake and the 1968 Tokachi-Oki earthquake from a viewpoint of the short-period range, Nat. Disas. Sci., 6(2), 1-26, 1984.

IZUTANI, Y., Analysis of accelerograms and prediction of strong ground motion based on a stochastic source model, Ph. D. Thesis, Tohoku Univ., 1983.

IZUTANI, Y. and T. HIRASAWA, Source characteristics of shallow earthquakes in the northern part of Sanriku-Oki region, Japan, J. Phys. Earth, 26, 275-297, 1978.

IzUTANI, Y. and T. HIRASAWA, Strong motion durations and source parameters, Prog. Abstr. Seismol. Soc. Jpn., No. 1, 197, 1984 (in Japanese).

IZUTANI, Y. and T. HIRASAWA, Rapid estimation of fault parameters for near-field tsunami warning, Nat. Disas. Sci., 9(1), 99-113, 1987.

KANAMORI, H., Synthesis of long-period surface waves and its application to earthquake source studies-Kurile Island earthquake of October 13, 1963, J. Geophys. Res., 75, $5011-5027,1970$ a.

KANAMORI, H., The Alaska earthquake of 1964: Radiation of long-period surface waves and source mechanism, J. Geophys. Res., 75, 5029-5040, 1970 b.

KANAMORI, H., Focal mechanism of the Tokachi-Oki earthquake of May 16, 1968: Contortion of the lithosphere at a junction of two trenches, Tectonophysics, 12, 1-13, 1971.

KANAMORI, H., Long-period ground motion in the epicentral area of major earthquakes, Tectonophysics, 21, 341-356, 1974.

KANAMORI, H., A numerical experiment on seismic tsunami warning network for Alaska and the Aleutians, Proc. Inter. Tsunami Symp., 30-39, 1985.

KanAmori, H. and J. J. Cipar, Focal process of the great Chilean earthquake of May 22, 1960, Phys. Earth. Planet. Inter., 9, 128-136, 1974.

KANAMORI, H. and J. W. Given, Use of long-period surface waves for rapid determination of earthquake source parameters, Phys. Earth Planet. Inter., 27, 8-31, 1981.

KANAMORI, H. and J. W. Given, Use of long-period seismic waves for rapid evaluation of tsunami potential of large earthquakes, in Tsunamis-Their Science and Engineering, ed. 
K. Iida and T. Iwasaki, pp. 37-49, Terra Scientific Pub. Co., Tokyo, 1983.

KIKUCHI, M. and Y. FUKAO, Iterative deconvolution of complex body waves from great earthquakes - the Tokachi-Oki earthquake of 1968, Phys. Earth Planet. Inter., 37, 235-248, 1985.

Kurata, E. and S. Noda, Annual report on strong-motion earthquake records in Japanese ports (1981), Tech. Note Port Harbour Res. Inst., No. 426, 1-191, 1982.

Kurata, E., T. FuKuhara, and S. Noda, Annual report on strong-motion earthquake records in Japanese ports (1982), Tech. Note Port Harbour Res. Inst., No. 446, 1-183, $1983 \mathrm{a}$.

Kurata, E., T. Fukuhara, and S. NodA, Strong-motion earthquake records on the 1983 Nipponkai-Chubu earthquake in port areas, Tech. Note Port Harbour Res. Inst., No. 458, 1-372, 1983 b.

KURATA, E., S. IAI, and H. TsuchidA, Annual report on strong-motion earthquake records in Japanese ports (1975), Tech. Note Port Harbour Res. Inst., No. 236, 1-64, 1976.

Kurata, E., T. IshizaKa, and H. Tsuchida, Annual report on strong-motion earthquake records in Japanese ports (1971), Tech. Note Port Harbour Res. Inst., No. 136, 1-195, 1972.

Kurata, E., T. IshizaKa, and H. Tsuchida, Annual report on strong-motion earthquake records in Japanese ports (1972), Tech. Note Port Harbour Res. Inst., No. 160, 1-206, 1973.

KuRATA, E., T. IshizaKa, and H. Tsuchida, Annual report on strong-motion earthquake records in Japanese ports (1973), Tech. Note Port Harbour Res. Inst., No. 181, 1-152, 1974.

Kurata, E., T. IshizaKa, and H. Tsuchida, Annual report on strong-motion earthquake records in Japanese ports (1974), Tech. Note Port Harbour Res. Inst., No. 202, 1-124, 1975.

KuRATA, E., S: IAI, Y. YokoYama, and H. TSUCHIDA, Strong-motion earthquake records on the 1978 Miyagi-Ken-Oki earthquake in port areas, Tech. Note Port Harbour Res. Inst., No. 319, 1-419, 1979.

Kurata, E., S. IaI, Y. Yokoyama, and H. Tsuchida, Annual report on strong-motion earthquake records in Japanese ports (1978 and 1979), Tech. Note Port Harbour Res. Inst., No. 338, 1-519, 1980.

MoRI, J. and K. ShImaZAKI, High stress drops of short-period subevents from the 1968 Tokachi-Oki earthquake as observed on strong motion records, Bull. Seismol. Soc. Am., 74, 1529-1544, 1984.

MORI, J. and K. SHIMAZAKI, Inversion of intermediate-period Rayleigh waves for source characteristics of the 1968 Tokachi-Oki earthquake, J. Geophys. Res., 90, 11374-11382, 1985.

NaGAmUne, T., Source regions of great earthquakes, Geophys. Mag., 35, 333-399, 1971.

NAKAGAWA, T. and Y. OYANAGI, Program system SALS for nonlinear least-squares fitting in experimental sciences, in Recent Developments in Statistical Inference and Data Analysis, ed. K. Matsushita, pp. 221-225, North Holland Pub. Co., Amsterdam, 1980.

OKAL, E. A. and J. TALANDIER, T-wave duration, magnitudes and seismic moment of an earthquake-Application to tsunami warning, J. Phys. Earth, 34, 19-42, 1986.

OTSUKA, M., Earthquake magnitude and surface fault formation, J. Phys. Earth, 12, 19-24, 1964. 
SchwartZ, S. Y. and L. RuFF, The 1968 Tokachi-Oki and the 1969 Kurile Islands earthquakes: Variability in the rupture process, J. Geophys. Res., 90, 8613-8626, 1985.

SENo, T., K. IsHIBASHI, and K. Sudo, Rupture process of the Miyagi-Ken-Oki earthquake of February 20, 1978, Prog. Abstr. Seismol. Soc. Jpn., No. 1, 96, 1978 (in Japanese).

Seno, T., K. Shimazaki, P. Somerville, K. Sudo, and T. Eguchi, Rupture process of the Miyagi-Oki, Japan earthquake of June 12, 1978, Phys. Earth Planet. Inter., 23, 39-61, 1980.

SHIMAZAKI, K., Nemuro-Oki earthquake of June 17, 1973: A lithospheric rebound at the upper half of the interface, Phys. Earth Planet. Inter., 9, 314-327, 1974.

SHIMAZAKI, K. and J. MoRI, Focal mechanism of the May 26, 1983 Japan Sea earthquake, Prog. Abstr. Seismol. Soc. Jpn., No. 2, 15, 1983.

Sudo, K., K. IsHibashi, and T. SaSatani, Source mechanism of the Hokkaido-Toho-Oki earthquake of March 24, 1978, Prog. Abstr. Seismol. Soc. Jpn., No. 2, 44, 1978 (in Japanese).

TAKeo, M., M. Kasahara, and K. AbE, Source process of the 1982 Urakawa-Oki earthquake, Prog. Abstr. Seismol. Soc. Jpn., No. 2, 2, 1982 (in Japanese).

TrIFUNAC, M. D. and A. G. BRADY, A study on the duration of strong earthquake ground motion, Bull. Seismol. Soc. Am., 65, 581-626, 1975.

TsuchiDA, H., E. Kurata, and K. Sudo, Strong-motion earthquake records on the 1968 Tokachi-Oki earthquake and its aftershocks, Tech. Note Port Harbour Res. Inst., No. 80, $1-476,1969$.

Tsuchida, H., E. Kurata, and K. Sudo, Annual report on strong-motion earthquake records in Japanese ports (1968), Tech. Note Port Harbour Res. Inst., No. 98, 1-342, $1970 \mathrm{a}$.

TsuchiDA, H., E. Kurata, and K. Sudo, Annual report on strong-motion earthquake records in Japanese ports (1969), Tech. Note Port Harbour Res. Inst., No. 100, 1-86, $1970 \mathrm{~b}$.

Tsuchida, H., E. Kurata, and K. Sudo, Annual report on strong-motion earthquake records in Japanese ports (1970), Tech. Note Port Harbour Res. Inst., No. 116, 1-171, 1971.

YoshioKA, N. and K. ABE, Focal mechanism of the Iwate-Oki earthquake of June 12, 1968, J. Phys. Earth, 24, 251-262, 1976. 